\title{
Molhabilidade da madeira de Maçaranduba (Manilkara huberi) in natura
}

\author{
Dayane Targino de Medeiros ${ }^{1 *}$, Felipe Gomes Batista ${ }^{1}$, Rafael Rodolfo de Melo $^{2}$, Pedro Henrique \\ Gonzalez de Cademartori ${ }^{3}$, Ivana Amorim Dias ${ }^{3}$, Carlos Fran Ferreira Dantas ${ }^{4}$
}

\begin{abstract}
RESUMO: Este trabalho teve como objetivo analisar a molhabilidade superficial da madeira da espécie Manilkara huberi (Maçaranduba) aplicando-se dois tipos de substâncias. Para isso, utilizou-se o goniômetro na obtenção dos ângulos de contato, no qual empregou-se três amostras com dimensões de 2,5 x 2,5 x 1,8 cm, em que estas foram lixadas com lixa 220. Os líquidos foram água destilada e formamida, com o volume da gota de $5 \mu \mathrm{L}$. Verificou-se que a madeira de Maçaranduba apresentou diferenciação na molhabilidade de sua superfície, tanto nos tipos de líquidos quanto nos tempos observados, em que, a água expôs os ângulos mais elevados. A substância formamida demostrou baixo ângulo de contato e se diferenciou nos dois tempos avaliados.
\end{abstract}

Palavras-chave: ângulo de contato, água, formamida.

\section{Maçaranduba wood wettability (Manilkara huberi) in natura}

\begin{abstract}
This work aimed to analyze the surface wettability of wood of the species Manilkara huberi (Maçaranduba) by applying two types of substances. For this, the goniometer was used to obtain the contact angles, in which three samples with dimensions of 2,5 × 2,5 x 1,8 cm were used, in which they were sanded with sandpaper 220. The liquids were distilled water and formamide, with the drop volume of $5 \mu \mathrm{L}$. It was verified that maçaranduba wood presented differentiation in the wettability of its surface, both in the types of liquids and in the times observed, in which the water exposed the highest angles. The formamide substance showed low contact angle and differed in the two times evaluated.
\end{abstract}

Keywords: contact angle, water, formamide.

\section{INTRODUÇÃO}

A espécie Maçaranduba (Manilkara huberi) possui uma madeira com grande relevância na economia, tendo em vista que sua densidade é de aproximadamente $1,00 \mathrm{~g} / \mathrm{cm}^{3}$, sendo bastante utilizada na confecção de móveis sofisticados, instrumentos musicais modernos, fabricação de embarcações navais, como peça estrutural na construção civil e outros usos básicos (HIRAI et al., 2008). Contém uma durabilidade natural expressiva ao ter contato direto com solos, e por isso é indicada para uso em cercas, postes e assoalhos (GOMES et al., 2005).

Desta forma, avaliar as propriedades da madeira é um fator determinante de qualidade, e dentre as análises realizadas, temos a de superfície, que determina a molhabilidade de materiais lenhosos, na qual é obtida por meio do ângulo de contato. Esse ângulo é descrito de forma geométrica como o grau gerado pela intersecção de dois planos tangentes, considerando a superfície de um material sólido e a superfície de um líquido. Além de o contorno de contato entre os planos, comumente, vapor ou ar (BRISOLARI, 2008).
Existem numerosos líquidos que são empregues para o tratamento de superfícies madeireiras, como por exemplo, nos processos de acabamentos e preservação da madeira, bem como na colagem de lâminas para a produção de compensados (MELO, 2012). Por isso, faz-se necessário avaliar a absorção de líquidos em madeiras de diferentes espécies, para que se venha ter uma maior durabilidade de peças produzidas com madeira. Assim, o exposto trabalho teve como objetivo determinar o ângulo de contato da espécie conhecida popularmente como maçaranduba.

\section{MATERIAL E MÉTODOS}

Para a realização do estudo, utilizou-se dois tipos de líquidos, a água destilada e Formamida, com o volume da gota de $5 \mu \mathrm{L}$, sendo postas no plano radial da madeira por três vezes em cada amostra. A medida do ângulo foi tomada em 5 (Ө5) e 10 segundos ( $(\Theta 10)$ após a disposição da gota. Usou-se o Goniômetro Krüss DSA30 acoplado a um computador com software DSA25 para a obtenção do ângulo de contato da espécie, considerando três amostras com dimensões de $2,5 \times 2,5 \times 1,8 \mathrm{~cm}$, em que foram

\footnotetext{
${ }^{1}$ Universidade Federal de Lavras

${ }^{2}$ Universidade Federal Rural do Semi-Árido

${ }^{3}$ Universidade Federal do Paraná

${ }^{4}$ Instituto Federal do Rio Grande do Norte

* Email: dayanemedeirost@gmail.com
} 
previamente lixadas com lixa de 220. Para a análise de comparação e diferenciação das médias da madeira tropical estudada, utilizou-se a análise de variância empregando o teste de Tukey com probabilidade de erro a $5 \%$.

\section{RESULTADOS E DISCUSSÃO}

Os resultados médios referentes à molhabilidade da madeira de Maçaranduba se encontram na Tabela
1. Em que, observou-se uma diminuição do ângulo de contato em relação ao tempo, de 5 para 10 segundos, tanto com a água quanto na utilização de Formamida. Contudo, não houve diferenciação estatística da água em relação ao tempo, ao contrário da Formamida, que apresentou valores distintos.

Tabela 1. Resultados médios da molhabilidade obtidos para a espécie Manilkara huberi.

\begin{tabular}{ccc}
\hline Líquido & $\Theta 5 \mathrm{~s}$ & $\Theta 10 \mathrm{~s}$ \\
\hline Água & $107,21 \pm 8,16 \mathrm{Aa}$ & $105,15 \pm 8,84 \mathrm{Aa}$ \\
Formamida & $78,74 \pm 4,78 \mathrm{Ab}$ & $73,11 \pm 4,46 \mathrm{Bb}$ \\
\hline
\end{tabular}

*Valores seguidos por letras minúsculas distintas em uma mesma coluna diferem estatisticamente pelo teste de Tukey a $95 \%$ de probabilidade, e valores com letras maiúsculas diferentes entre colunas do mesmo parâmetro.

De acordo com Sheldon; Gardner (2001), quando um líquido entra em contato com a superfície de uma madeira, primeiramente, o ângulo tende a diminuir significativamente, sendo definido como a fase de espalhamento. Logo após, a redução do ângulo ocorre aos poucos, até manter-se em equilíbrio, etapa de difusão.

Quanto ao tipo de líquido, verifica-se que a substância Formamida exibiu menores ângulos quando comparada com a água, apresentando então, características de materiais molhantes. Enquanto, a água expressou valores superiores a $100^{\circ}$, expressando hidrofobicidade superficial.

No estudo de Borzi (2014) a espécie tropical conhecida como jatobá, apresentou ângulo de contato de $40,78^{\circ}$ nos primeiros $5 \mathrm{~s}$ e $40,10^{\circ}$ em 10 s após a inserção da gota de água na madeira com a superfície in natura, sendo então, valores inferiores aos encontrados neste estudo.

Conforme Ugulino; Hernández (2015), materiais que são previamente lixados antes da obtenção da molhabilidade, tendem a possuir maiores valores de ângulo, isso acontece em função do aumento das áreas de hidroxilas expostas na face da madeira.

A variação da molhabilidade quanto aos líquidos dispostos na superfície de madeiras, ocorre devido ao tipo de espécie e plano de corte, idade, tratamento superficial e entre outras peculiaridades intrínsecas ao material (BRISOLARI, 2008).

\section{CONCLUSÃO}

A madeira da espécie maçaranduba apresentou diferenciação na molhabilidade de sua superfície, no qual a água exibiu os maiores ângulos e não deferiu estatisticamente de 5 para 10 segundos, expressando capacidade de repulsão a água. Já a substância Formamida demostrou baixo ângulo de contato e se diferenciou nos dois tempos analisados, causando absorção elevada conforme o tempo.

\section{REFERÊNCIAS}

BORZI, R. F. G. Colorimetria e molhabilidade em piso engenheirado. 2014. 42 f. Trabalho de conclusão de curso (Bacharelado em Engenharia Industrial Madeireira) Universidade Federal do Paraná, Curitiba.

BRISOLARI, A. Estudo da molhabilidade em madeiras tropicais ou de reflorestamento por medidas de ângulo de contato e de permeabilidade. $2008.98 \mathrm{f}$. Dissertação (Mestrado em ciência e Engenharia de Materiais) Universidade de São Paulo, São Carlos.

GOMES, J. I.; SILVA, E. M. A.; MELO, A. T. S. Durabilidade de 15 espécies de madeiras amazônicas em contato com o solo em ambiente sombreado. Comunicado Técnico, Embrapa Amazônia Oriental, Belém, n. 148, p. $1-4,2005$.

HIRAI, E. H.; CARVALHO, J. O. P.; PINHEIRO, K. A. O. Estrutura da população de maçaranduba (Manilkara huberi Standley) em 84 ha de floresta natural na fazenda rio capim, Paragominas, PA. Revista de Ciências Agrárias Amazonian Journal of Agricultural and Environmental Sciences, Belém, v. 49, n. 1 p. 65-76, 2008.

MELO, R. R. Avaliação de variáveis tecnológicas na produção de painéis LVL confeccionados com paricá (Schizolobium amazonicum Huber ex. Ducke). 2012. 166 f. Tese (Doutorado em Ciências Florestais) - Universidade de Brasília, Brasília.

SHELDON, S.; GARDNER, D. Dynamic adhesive wettability of wood. Wood and Fiber Science, Tokyo, v. 33, n. 1, p. 58-68, 2001.

UGULINO, B.; HERNÁNDEZ, R. E. Effects of four surfacing methods on surface properties and coating performance of red oak wood. Proceedings of the 22nd International Wood Machining Seminar June, Quebec City, p. 14-17, 2015. 